\title{
Glycation exacerbates the neuronal toxicity of $\beta$-amyloid
}

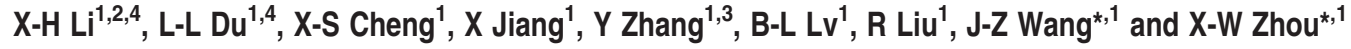

Accumulation evidence shows that $\beta$-amyloid $(A \beta)$ is a neurotoxic and accumulation of $A \beta$ is responsible for the pathology of Alzheimer's disease (AD). However, it is currently not fully understood what makes $A \beta$ toxic and accumulated. Previous studies demonstrate that $A \beta$ is a suitable substrate for glycation, producing one form of the advanced glycation endproducts (AGEs). We speculated that $A \beta$-AGE formation may exacerbate the neurotoxicity. To explore whether the $A \beta$-AGE is more toxic than the authentic $A \beta$ and to understand the molecular mechanisms, we synthesized glycated $A \beta$ by incubating $A \beta$ with methylglyoxal (MG) in vitro and identified the formation of glycated $A \beta$ by fluorescence spectrophotometer. Then, we treated the primary hippocampal neurons cultured 8 days in vitro with $A \beta$-AGE or $A \beta$ for $24 \mathrm{~h}$. We observed that glycation exacerbated neurotoxicity of $A \beta$ with upregulation of receptor for AGE (RAGE) and activation of glycogen synthase kinase-3 (GSK-3), whereas simultaneous application of RAGE antibody or GSK-3 inhibitor reversed the neuronal damages aggravated by glycated $A \beta$. Thereafter, we found that $A \beta$ is also glycated with an age-dependent elevation of AGEs in Tg2576 mice, whereas inhibition of $A \beta$-AGE formation by subcutaneously infusion of aminoguanidine for 3 months significantly rescued the early cognitive deficit in mice. Our data reveal for the first time that the glycated $A \beta$ is more toxic. We propose that the glycated $A \beta$ with the altered secondary structure may be a more suitable ligand than $A \beta$ for RAGE and subsequent activation of GSK-3 that can lead to cascade pathologies of $A D$, therefore glycated $A \beta$ may be a new therapeutic target for $A D$.

Cell Death and Disease (2013) 4, e673; doi:10.1038/cddis.2013.180; published online 13 June 2013

Subject Category: Neuroscience

Senile plaques (SP) and neurofibrillary tangles are hallmark pathologies in the brains of Alzheimer's disease (AD)., The major component in the plaques is $\beta$-amyloid $(A \beta)$, a peptide of 39-43 amino acids, produced from amyloid precursor protein (APP) by $\beta$-secretase pathway. ${ }^{3}$ Numerous studies show that the $A \beta$-induced neurotoxicity is responsible for the pathology of $A D .{ }^{4}$ However, what makes $\mathrm{A} \beta$ more toxic and which forms of $\mathrm{A} \beta$ are more toxic are elusive.

The plaques in the $A D$ brains are colocalized with the advanced glycation endproducts (AGEs), and the plaqueenriched fractions contain approximately threefold higher AGE adducts than that of the age-matched controls, ${ }^{5}$ suggesting that $\mathrm{A} \beta$ may be glycated. The long-live proteins are preferentially modified to form AGEs and the stability of $A \beta$ makes it an ideal substrate for non-enzymatic glycation and formation of AGEs. Although in vitro studies show that $A \beta$ can be glycated and the glycated $\mathrm{A} \beta$ contribute to the $\mathrm{A} \beta$ accumulation, ${ }^{5,6}$ it is currently not characterized whether $\mathrm{A} \beta$ is also glycated in vivo to form $A \beta$-AGEs and the role of $A \beta$ $A G E$ in the pathogenesis of $A D$.
Accumulation of AGEs in the brains may impair neural cells through direct covalent crosslinking to the substrates ${ }^{7,8}$ or binding to the surface AGE receptors, namely RAGEs. ${ }^{9}$ The ligand-receptor interaction may perturb cell functions by activating receptor-mediated signal transduction pathways. ${ }^{10}$ Interestingly, $A \beta$ has been identified as a ligand of RAGE. ${ }^{11}$ RAGE is overexpressed in the AD brains and acts as a binding site for $\mathrm{A} \beta$ at the plasma membrane of neurons, microglial cells, and endothelial cells of the vessel wall. ${ }^{11}$ Upregulation of RAGE mediates $\mathrm{A} \beta$-induced oxidative stress, ${ }^{12}$ activation of nuclear factor- $\kappa \mathrm{B},{ }^{11}$ neuronal expression of macrophage colony-stimulating factor, ${ }^{13}$ and cell death. ${ }^{14}$ Recent studies show that RAGE-dependent signaling contributes to an impaired learning/ memory in AD-like transgenic models. ${ }^{15}$ It is currently unknown whether RAGE mediates neurotoxicity induced by glycated $A \beta$.

Formation of AGEs involves nonenzymatic reactions of reducing sugars or dicarbonyl compounds, such as methylglyoxal (MG) and glyoxal, and abnormal glucose metabolism or oxidative stress can lead to the formation of the reactive dicarbonyl compounds. ${ }^{16}$ Aminoguanidine (AG) is a prototype scavenging agent that prevents the formation of AGEs from

\footnotetext{
${ }^{1}$ Department of Pathophysiology, Key Laboratory of Neurological Diseases of Ministry of Education, Tongji Medical College, Huazhong University of Science and Technology, Wuhan, China; ${ }^{2}$ Institute of Traumatic Brain Injury and Neurology, Pingjin Hospital, Logistics College of Chinese People's Armed Police Forces, Tianjin, China and ${ }^{3}$ Department of Gerontology, Li Yuan Hospital, Huazhong University of Science and Technology, Wuhan, China

${ }^{*}$ Corresponding author: X-W Zhou or J-Z Wang, Department of Pathophysiology, Key Laboratory of Neurological Diseases of Ministry of Education, Tongji Medical College, Huazhong University of Science and Technology, Wuhan 430030, China. Tel: + 8627 83693883; Fax: + 8627 83693883; E-mail: zhouxinwen@mail.hust.edu.cn or wangjz@mails.tjmu.edu.cn

${ }^{4}$ These authors contributed equally to this work.

Keywords: Glycated $A \beta$; receptor for advanced glycation endproducts; aminoguanidine; glycogen synthase kinase-3

Abbreviations: $A \beta, \beta$-amyloid; AD, Alzheimer's disease; AG, aminoguanidine; AGEs, advanced glycation endproducts; APP, amyloid precursor protein; BACE1, b-site APP cleaving enzyme 1; CD, circular dichroism; MG, methylglyoxal; GSK-3, glycogen synthase kinase-3; NS, normal saline; PHF, paired helical filament; RAGE, receptor for AGEs; SP, senile plaques; Tg, Tg2576; Tg2576 Mice, APP transgenic mice; mAb, monoclonal antibody; pAb, polyclonal antibody

Received 07.1.13; revised 11.4.13; accepted 30.4.13; Edited by A Verkhratsky
} 
the dicarbonyl precursors both in vitro and in vivo. ${ }^{17} \mathrm{AG}$ reduces tissue AGEs accumulation and inhibits the vascular and renal manifestations induced by experimental diabetes ${ }^{18}$ or AGEs administration. ${ }^{5}$ Recent studies show that AG prevents hippocampal alterations in streptozotocin-induced dementia in rat $^{19}$ and protected neuroblastoma cells against the neurotoxic effects of MG. ${ }^{20}$

Based on the previous findings, we hypothesized that glycated $\mathrm{A} \beta$ in vitro could exacerbate the neurotoxicity of $\mathrm{A} \beta$, and in vivo inhibition of AGEs partially constituted by $\mathrm{A} \beta$-AGE could restore early cognitive decline of $A D$.

\section{Results}

Glycation exacerbates neurotoxicity of $A \beta$ in hippocampal neurons. To synthesize $A \beta$-AGE in vitro, $A \beta 1-42$ was incubated with $M G$ for 1 month. The production of $A \beta-A G E$ was identified with fluorescence spectrophotometer measuring AGE-specific fluorescence at emission of $440 \mathrm{~nm}$ and excitation of $370 \mathrm{~nm}$. We observed that the fluorescence of $A \beta$-AGE was about seven times as much as $\mathrm{A} \beta 1-42$ (data not shown), suggesting $A \beta$-AGE had been successfully produced in vitro.

To explore whether $\mathrm{A} \beta$-AGE is more toxic than authentic $\mathrm{A} \beta$, 8-DIV embryonic hippocampal neurons were treated with $\mathrm{A} \beta$ or $\mathrm{A} \beta$-AGE for $24 \mathrm{~h}$. We found that $\mathrm{A} \beta$-AGE was more toxic than $A \beta$ in decreasing cell viability, increasing cell apoptosis, inducing tau hyperphosphorylation, and reducing synaptic proteins (Figures 1a-f). By circular dichroism (CD) spectra analysis, we found that $A \beta$-AGE displayed a significantly different profile (secondary structure) from $A \beta$ (Figure $1 \mathrm{~g}$ ), which may underlie exacerbating toxicity of $A \beta$-AGE. Activation of RAGE and glycogen synthase kinase-3
(GSK-3) mediates A $\beta$-AGE-exacerbated neurotoxicity in
hippocampal neurons and Tg2576 mice. RAGE is the
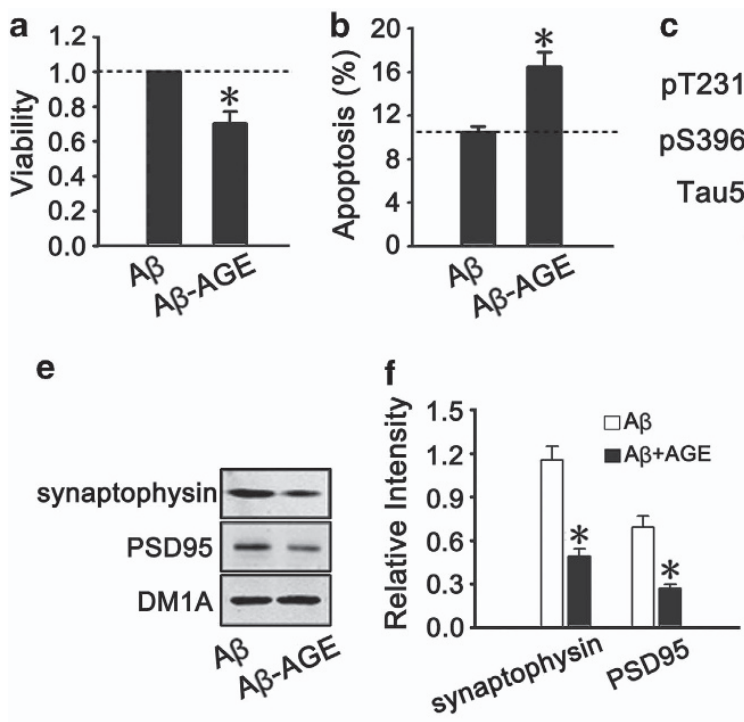

common receptor of $\mathrm{A} \beta$ and AGEs. To verify whether $A \beta$-AGE induces the neurotoxicity through RAGE, we first measured the level of RAGE after $\mathrm{A} \beta$ or $\mathrm{A} \beta$-AGE treatment. We found that both $A \beta-A G E$ and $A \beta$ increased RAGE level, but the level of RAGE was even higher in $A \beta$-AGE group (Figures 2a-c). By using RAGE antibody to block the receptor, we found that blockage of RAGE almost abolished the $A \beta$-AGE-induced reduction of cell viability (Figure $2 d$ ), elevation of apoptotic rate (Figure 2e), tau hyperphosphorylation (Figures $2 f$ and $g$ ) and deficits of synaptic proteins (Figures $2 \mathrm{~h}$ and i). These data indicate that $\mathrm{A} \beta$-AGE may be a more suitable ligand for RAGE than $A \beta$ in exacerbating the $\mathrm{A} \beta$-induced neurotoxicity.

We have recently reported that $A G E s$ induces cognitive impairment in SD rats through RAGE/GSK-3 pathway. ${ }^{21}$ To explore the involvement of GSK-3 in A $\beta$-AGE-induced neural impairments, we measured the activity-dependent phosphorylation of GSK-3 $\beta$ at Ser9 by western blot (Figures 3a and b) and immunofluorescence (Figure 3c). The phosphorylated GSK-3 $\beta$ at Ser9 decreased significantly in A $\beta$-AGE group than in $A \beta$ group, suggesting that higher GSK-3 activity in A $\beta$-AGE group than the $A \beta$ group. These data indicate that upregulation of GSK-3 may be involved in A $\beta$-AGE-induced toxicities. To further verify the role of GSK-3, we used inhibitor of GSK-3. We found that simultaneous inhibition of GSK-3 by $\mathrm{LiCl}$ attenuated the $\mathrm{A} \beta$-AGE-induced reduction of cell viability (Figure $3 d$ ), elevation of apoptosis rate (Figure $3 e$ ), tau hyperphosphorylation (Figures $3 f$ and $g$ ) and decline of synaptic proteins (Figures $3 \mathrm{~h}$ and i). These data suggest that GSK-3 may mediate the A $\beta$-AGE-induced exacerbation of neural impairments.

It is well known that Akt can phosphorylate GSK-3 $\beta$ at Ser9 and thus inhibit the kinase. ${ }^{22}$ Therefore, we measured the activity-dependent phosphorylation level of Akt. We found that phosphorylation of Akt at Thr473 was remarkably decreased
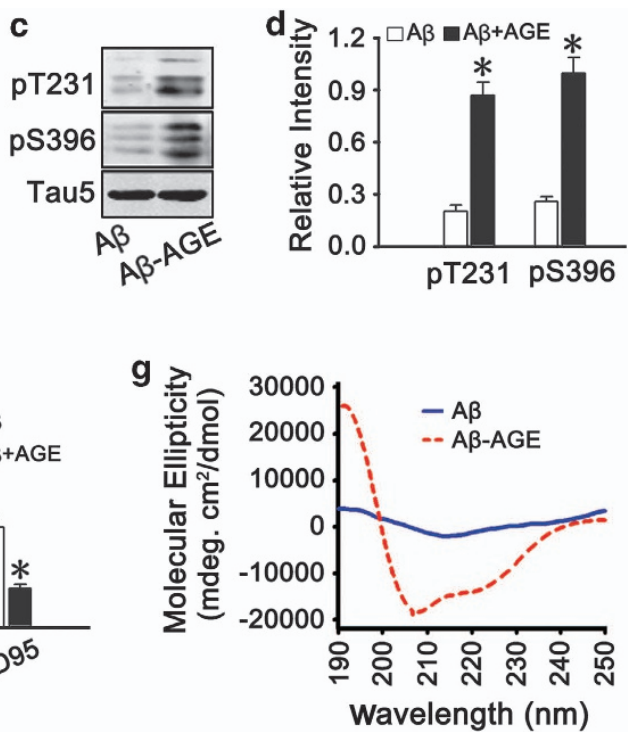

Figure $1 \mathrm{~A} \beta$-AGE with a special CD profile is more toxic to hippocampal neurons than the authentic $\mathrm{A} \beta$. (a-f) The hippocampal neurons cultured $8 \mathrm{DIV}$ were treated with $\mathrm{A} \beta$ or $\mathrm{A} \beta$-AGE for $24 \mathrm{~h}$, then the viability of the neurons was analyzed by using CCK- 8 kit $(\mathbf{a})$; the apoptosis rate was examined by flow cytometry (b); the level of tau phosphorylation at Thr231 and Ser396 (c and d) and synaptic proteins (e and f) were analyzed by western blot. Levels of phosphorylated tau and synaptic proteins were normalized, respectively, to Tau-5 and DM1A. (g) A $\beta$ or A $\beta$-AGE was prepared in vitro as described in the methods and the structural property was measured by CD spectra analysis. $n=3,{ }^{*} P<0.01$ versus $\mathrm{A} \beta$ group 

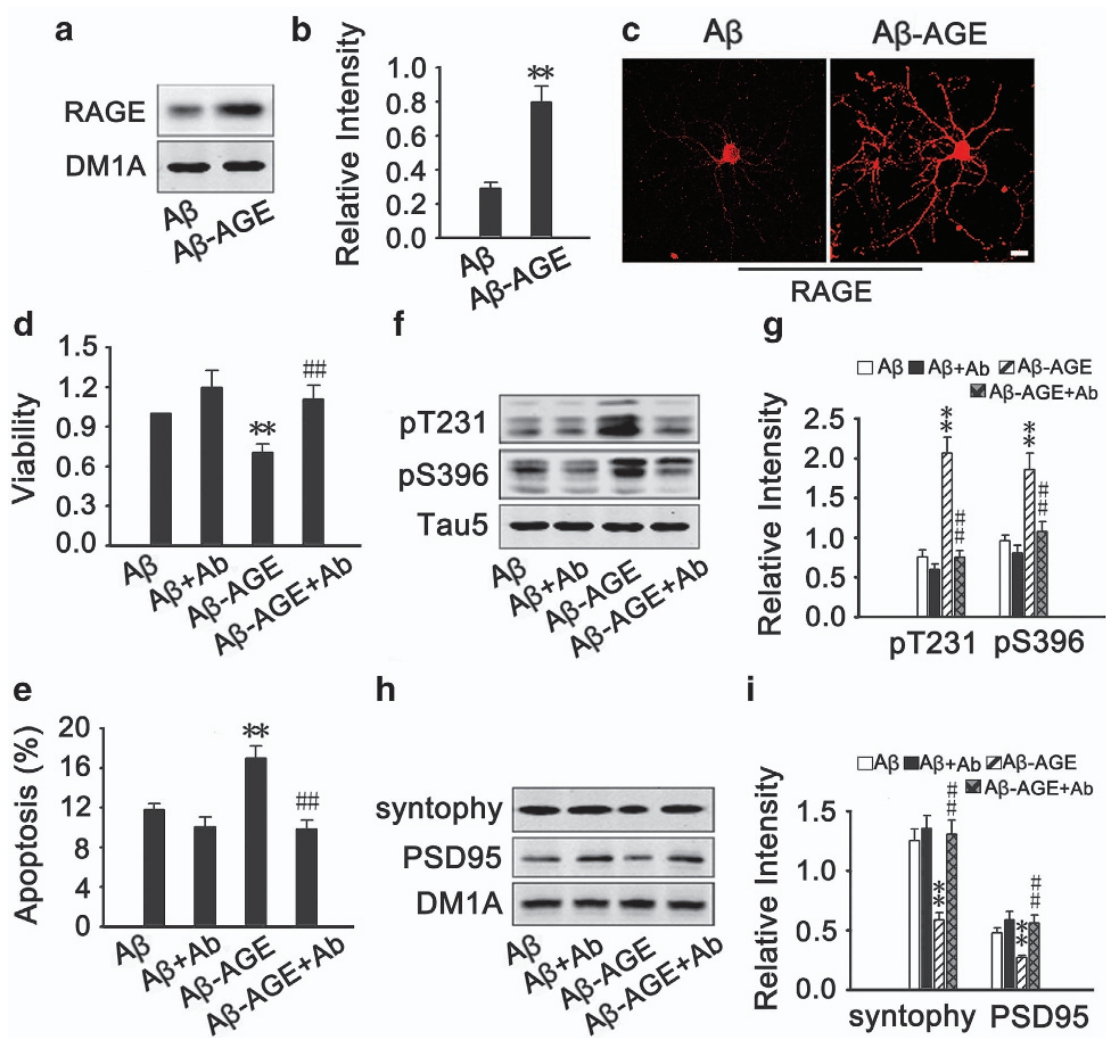

h

i
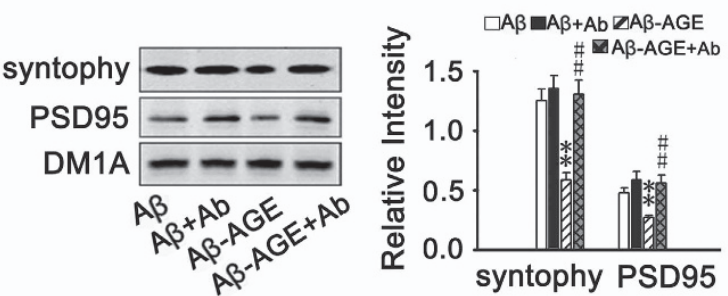

Figure 2 Upregulation of RAGE mediates the exacerbated A $\beta$-AGE toxicity in hippocampal neurons. (a-c) The hippocampal neurons cultured 8 DIV were treated with A $\beta$ or $A \beta$-AGE for $24 \mathrm{~h}$, then the level of RAGE was analyzed by western blot and immunofluorescence staining. (d-i) The hippocampal neurons cultured 8 DIV were preincubated with or without RAGE antibody (Ab) before treatment of $A \beta$ or $A \beta$-AGE for $24 \mathrm{~h}$, then the viability (d), the apoptotic rate (e), levels of the phosphorylated tau (f and $\mathbf{g}$ ), and synaptic proteins $(h, i)$ were measured. The level of RAGE and synaptic proteins was normalized to DM1A, and phosphorylated tau was normalized to Tau-5. $n=3$, ${ }^{*} P<0.01$ versus $A \beta$ group; ${ }^{\#} P<0.01$ versus $A \beta$-AGE group. Scale bar in $\mathbf{c}, 50 \mu \mathrm{m}$

after $\mathrm{A} \beta$-AGE treatment (Figures $3 \mathrm{j}$ and $\mathrm{k}$ ). These data suggest that inhibition of Akt may be upstream of the GSK-3 activation by $\mathrm{A} \beta$-AGE.

$A \beta$ is glycated to form $A \beta$-AGE with an age-dependent elevation of AGEs in the brains of Tg2576 mice. By western blot, we observed that the level of AGEs indeed increased significantly in hippocampus of a 9-month-old Tg2576 mice (Figures $4 \mathrm{a}$ and b). To verify whether $\mathrm{A} \beta$ is glycated, we analyzed the component of AGEs in a 9-monthold Tg2576 mice by coimmunoprecipitation and western blot. We found that $A \beta$ was co-immunoprecipitated with an antibody against $A G E s$ and vice versa (Figures $4 c$ and $d$ ), suggesting that the glycated $A \beta$ (A $\beta-A G E)$ may be one of the major component of AGEs in Tg2576 mice.

Early inhibiting the $A \beta$-AGE formation rescues cognitive impairment in Tg2576 mice. To verify the toxic roles of $A \beta$ AGE, we injected subcutaneously $A G$, an inhibitor of AGE formation, into Tg2576 mice for 3 months, started at 6 -months old, and then measured the level of AGEs, $A \beta$, and $A \beta$-AGE by dot blot, ELISA and immunoprecipitation, respectively. We found that $A G$ treatment decreased the levels of AGEs compared with normal saline (NS) group (Figure $5 \mathrm{a}$ ) and $A \beta$ in both of the cortex and the hippocampus (Figures $5 b$ and $c$ ), simultaneously, the levels of AGE-associated $A \beta$ and the $A \beta$-associated AGEs were reduced remarkably (Figures $5 \mathrm{~d}-\mathrm{g}$ ). These data confirm that $\mathrm{A} \beta$ is glycated and $A G$ inhibits the formation of $A \beta$-AGE in Tg2576 mice glycation.

To test whether inhibition of $A \beta$-AGE by AG could rescue the cognitive impairments, we trained 9-month-old Tg2576 mice administrated with AG or NS for 3 months in water maze for 6 days, and tested the memory retention. We found that AG treatment improved the learning and memory of the mice, demonstrated by decreased latency (Figure 6a), increased platform crossings (Figure $6 \mathrm{~b}$ ) and increased time spent in target quadrant (Figure 6c). These data suggest that inhibition of A $\beta$-AGE can rescue learning and memory in Tg2576 mice.

We also found that both pre-synaptic (synapsin I, synaptophysin, and VAMP2) and post-synaptic proteins (NR2A, NR2B, PSD93, and PSD95), as well as memory-associated proteins (c-fos and arc) were downregulated in 9-month-old Tg2576 mice, and administration of $A G$ restored the levels of the synaptic and memory-associated proteins (Figures $6 \mathrm{~d}$ and e). In addition, tau was hyperphosphorylated at Thr231 and Ser396 but not at Ser404, Thr205, and Ser198/199/202 (Tau-1 epitope) in 9-month-old Tg2576 mice, and AG treatment attenuated tau hyperphosphorylation (Figures $6 f-h$ ). These data suggest that inhibiting formation of AGEs, which included $\mathrm{A} \beta$-AGE, attenuates the neuropathology, which can contribute to the improved cognition of the mice. These in vivo data 

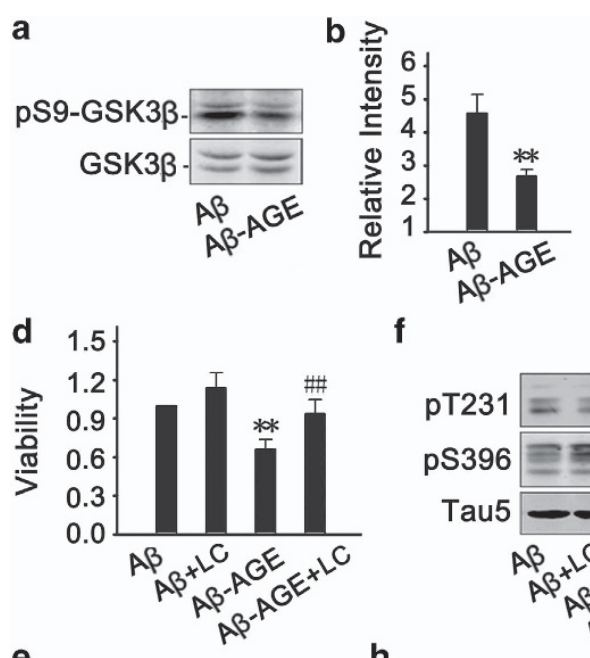

$\mathbf{f}$

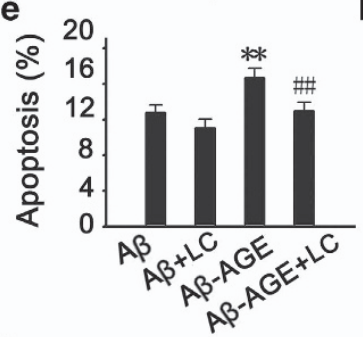

j
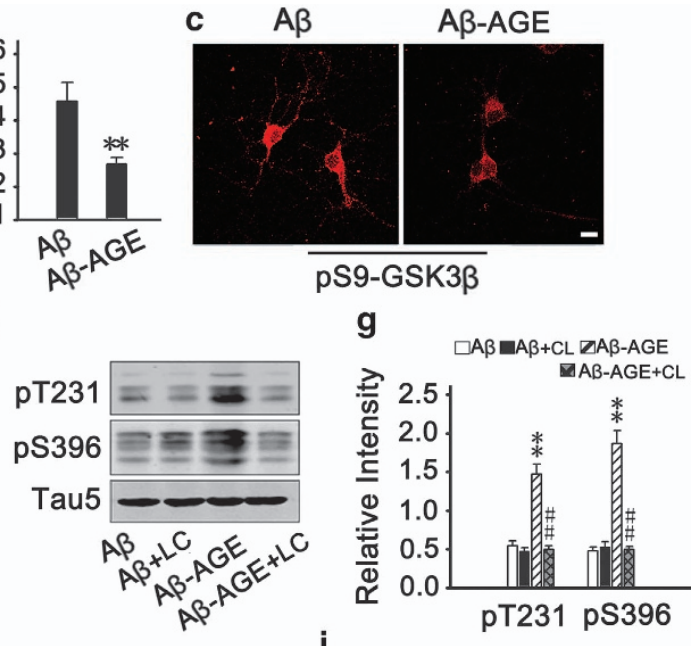

$$
\text { syn }
$$
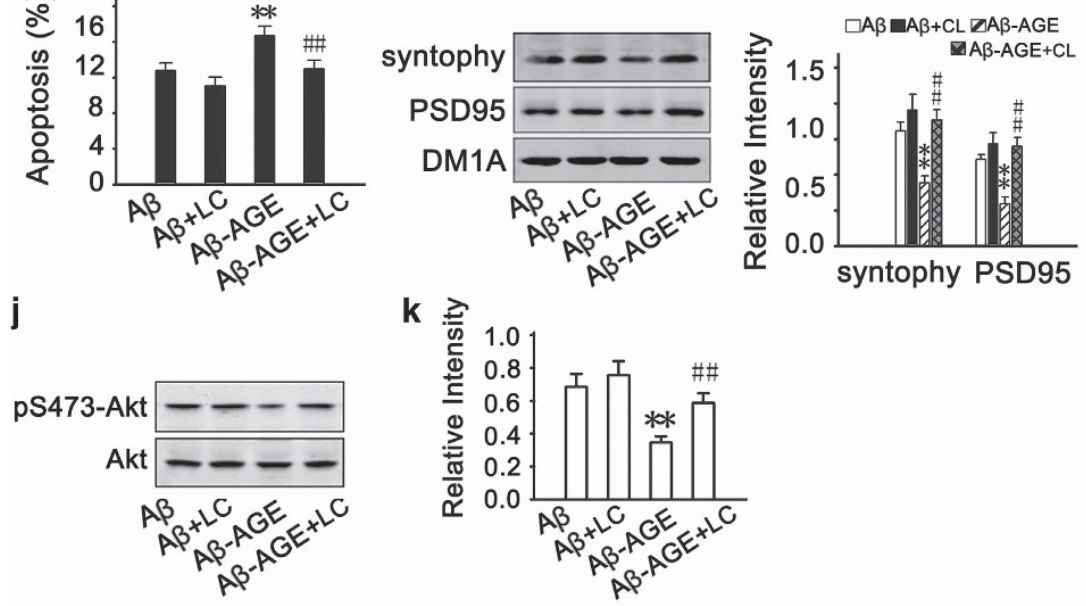

Figure 3 Activation of GSK-3 $\beta$ is involved in the exacerbated neurotoxicity of A $\beta$-AGE in hippocampal neurons. (a-c) Hippocampal neurons cultured 8 DIV were treated with $A \beta$ or A $\beta$-AGE for $24 \mathrm{~h}$, then the level of phosphorylated GSK-3 $\beta$ at Ser9 (inactive form) was measured by western blot (a and $\mathbf{b}$ ) and immunofluorescence (c). (d-k) Hippocampal neurons cultured 8 DIV were pre-incubated with or without LiCl (inhibitor of GSK-3) before treatment of A $\beta$ or A $\beta$-AGE for $24 \mathrm{~h}$. Then the neuron viability (d), the apoptotic rate (e), levels of the phosphorylated tau ( $\mathbf{f}$ and $\mathbf{g}$ ), synaptic proteins ( $\mathbf{h}$ and $\mathbf{i})$, and Akt $(\mathbf{j}$ and $\mathbf{k}$ ) were measured. The level of phosphorylated GSK-3 $\beta$, phosphorylated tau, synaptic proteins, and phosphorylated Akt was normalized, respectively, to GSK-3 $\beta$, Tau5, DM1A, and Akt. Li: LiCl. $n=3,{ }^{*} P<0.01$ versus A $\beta$ group. ${ }^{\#} P<0.01$ versus $\mathrm{A} \beta$-AGE group. Scale bar in c, $50 \mu \mathrm{m}$

partially demonstrated the enhanced neurotoxicity of $\mathrm{A} \beta$-AGE observed during in vitro experiments.

In view that the involvement of RAGE/GSK3 pathway in $\mathrm{A} \beta$-AGE-induced exacerbation of neurotoxicity was found in hippocampal neurons, we also examined the level alteration of RAGE and activity of GSK-3 in Tg2576 mice after treatment with AG. We found that the level of RAGE increased and GSK3 was activated in 9-month-old Tg2576 mice, whereas treatment of $A G$ attenuated the upregulation of RAGE and GSK-3 in the mice (Figure 7). These in vivo data further support that RAGE and GSK-3 are participated in A $\beta$-AGEinduced neurotoxicity.

\section{Discussion}

In type 2 diabetes mellitus (T2D) patients, the consequence of the elevated blood glucose leads to the generation of AGEs. Previous study showed that the increased AGEs contribute to the failure of sensory nerve regeneration in diabetes, ${ }^{23}$ and administration of exogenous AGE-modified proteins modulates the maturation and functions of peripheral blood dendritic cells and neural stem cells. ${ }^{24}$ Epidemiological studies have shown that diabetes mellitus is an independent risky factor of AD. ${ }^{25-28}$ However, the molecular mechanism is not fully understood. As the therapeutics advances for diabetes, the T2D patients will most likely live longer and thus the world may soon be facing the daunting challenge of dealing with a new population of AD sufferers with T2D. ${ }^{29}$ One of the hallmark lesion observed in AD brain is the formation of SPs, which are composed of the $\mathrm{A} \beta$, derived from APP proteolysis. Studies suggest that accumulation of $\mathrm{A} \beta$, is responsible for the age-related memory decline in $A D$ model, ${ }^{30-32}$ however, it is not fully understood what may lead to $\mathrm{A} \beta$ accumulation and in which form $\mathrm{A} \beta$ may exert its toxic effects. Formation and accumulation of AGEs has been proposed to be involved in the evolution of $A D .^{33}$ The level of 
AGEs is increased in the $A D$ brains and the glycated $A \beta$ accumulation accelerates $A \beta$ deposition. ${ }^{5,34}$ The proteins with prolonged turnover, such as tau in paired helical filament and

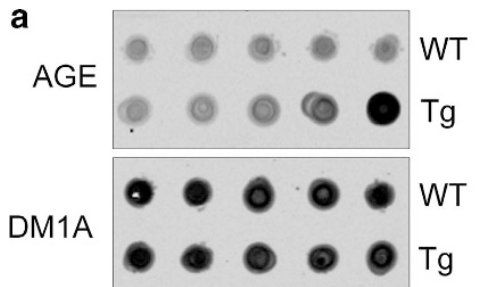

(m) $1 \quad \begin{array}{lllll}3 & 6 & 9 & 12\end{array}$
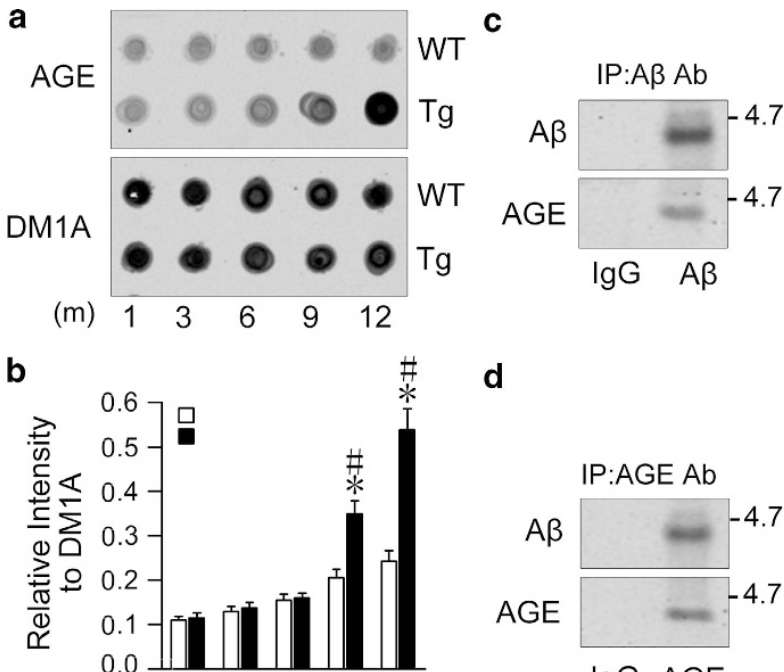

(m) $1 \quad 3 \quad 6 \quad 9 \quad 12$

d

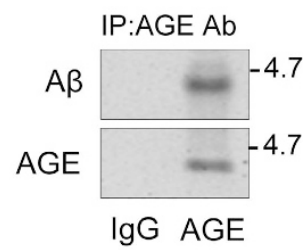

Figure $4 \quad A \beta$ is glycated with an age-dependent increase of AGE in the brains of Tg2576 mice. (a and b) The hippocampal extracts from Tg2576 (Tg) or wild-type (WT) mice at 1, 3, 6, 9, and 12 months were analyzed by dot blot using anti-AGE antibody normalized against DM1A (b). (c and d) The hippocampal extracts from 9-month-old Tg mice were precipitated with $A G E$ or $A \beta$ or lgG antibody, and then the level of $A \beta$ or AGE in the precipitate was measured by western blot using anti-A $\beta$ (c) or anti-AGE (d) antibody. $n=5,{ }^{*} P<0.01$ versus WT group; ${ }^{\#} P<0.01$ versus 6 months in Tg group
$\mathrm{A} \beta$ in the $\mathrm{AD}$ brains, ${ }^{35}$ are favorable substrates for the formation of AGEs. Therefore, we speculate that the overproduced $\mathrm{A} \beta$ in Tg2576 mice may be glycated and the glycation may exacerbate the toxicity of $A \beta$.

To investigate the toxicity of glycated $\mathrm{A} \beta$, we synthesized glycated $\mathrm{A} \beta$ ( $\mathrm{A} \beta$-AGE) in vitro and treated the hippocampal neurons cultured 8 days in vitro. We observed that the $A \beta$ AGE was more toxic than the authentic $A \beta$ in decreasing the cell viability, increasing apoptosis, causing tau hyperphosphorylation and damaging the synapses. By CD spectra analysis, we also observed that the glycated $A \beta$ showed an un-ordered secondary structure, which favors protein aggregation. ${ }^{36}$

RAGE, a cell surface-binding site for $A \beta$ and AGEs, is upregulated in affected cerebral vessels, neurons, and microglia ${ }^{37,38}$ when $A \beta$ increases. RAGE mediates $A \beta$ transport across the blood-brain barrier and accumulation in the brain. ${ }^{39}$ Transgenic mice overexpressing mutant human APP and RAGE in neurons displayed earlier stage deficits of spatial learning/memory and more serious neuropathologic changes. ${ }^{40} \mathrm{~A}$ growing body of evidence demonstrates that increased expression of RAGE allows for more profound RAGE-induced cellular perturbation. ${ }^{4142}$ To explore whether A $\beta$-AGE affects RAGE and whether RAGE is involved in the exacerbation of neural toxicity of $A \beta-A G E$, we measured the level of RAGE in hippocampal neurons in vitro. We found that the RAGE level was higher in A $\beta$-AGEtreated cells than in the $\mathrm{A} \beta$-treated ones, whereas simultaneous application of RAGE antibody attenuated more significantly the neural damages induced by $A \beta$-AGE. These
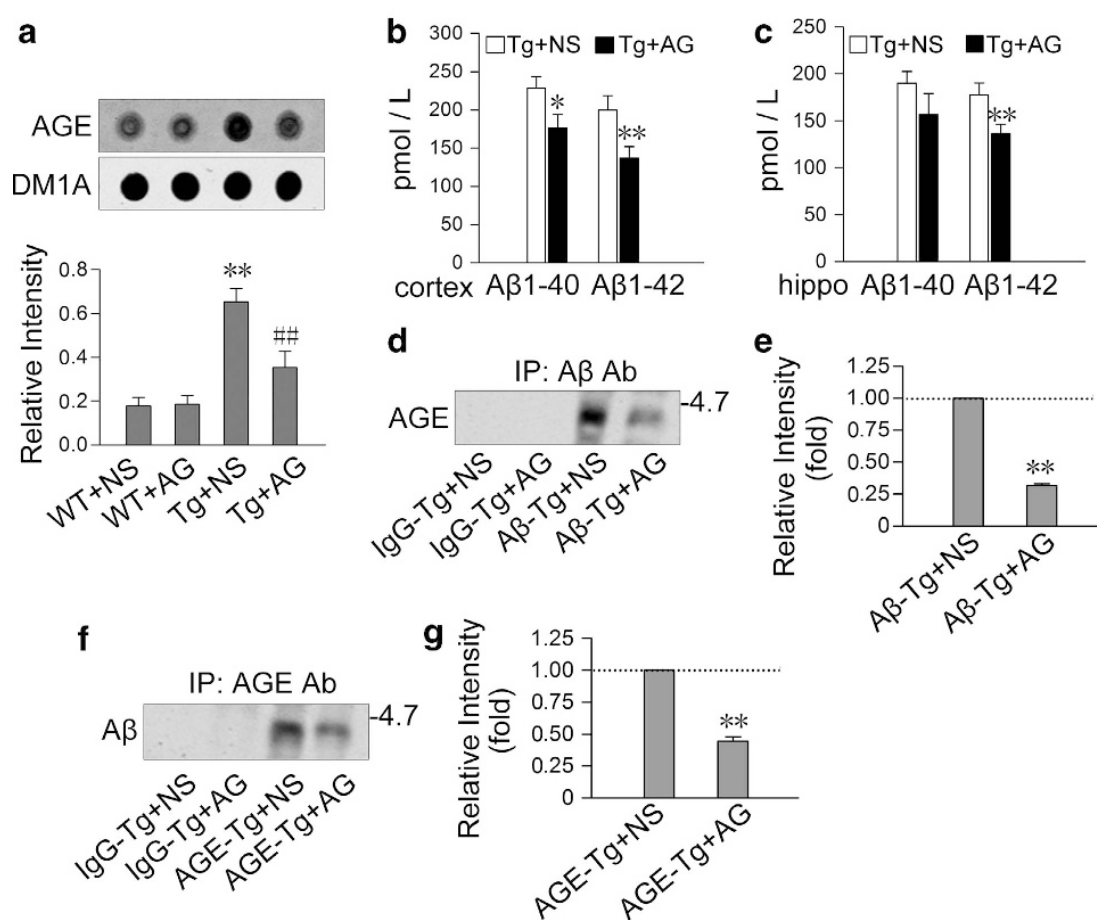

Figure 5 Subcutaneous injection of AG prevents formation of A $\beta$-AGE in Tg2576 mice. Tg2576 (Tg) mice and the wild-type (WT) littermates at 6-month old were subcutaneously injected with AG (blocker of AGE formation) or NS for 3 months. (a) Level of AGE in the cortex extracts was measured by dot blot and quantitated by normalization against DM1A. ${ }^{* *} P<0.01$ versus WT + NS group; ${ }^{\# \#} P<0.01$ versus $\mathrm{Tg}+$ NS group. (b and $\mathbf{c}$ ) The levels of $A \beta 1-40$ and $A \beta 1-42$ in cortex and hippocampus were estimated by ELISA. hippo: hippocampus. ${ }^{*} P<0.05,{ }^{* *} P<0.01$ versus $\mathrm{Tg}+$ NS group. $(\mathbf{d}-\mathbf{g})$ The cortex extracts were immunoprecipitated with $\lg G$ or $A G E$ or $A \beta$ antibody, and then the levels of $\mathrm{A} \beta$-AGE or AGEs in precipitate were measured by western blot using anti-A $\beta$ or anti-AGE antibody as indicated. ${ }^{*} P<0.01$ versus $\mathrm{A} \beta$ - $\mathrm{Tg}+\mathrm{NS}(\mathbf{e})$ or AGE-Tg $+\mathrm{NS}$ group (g) 

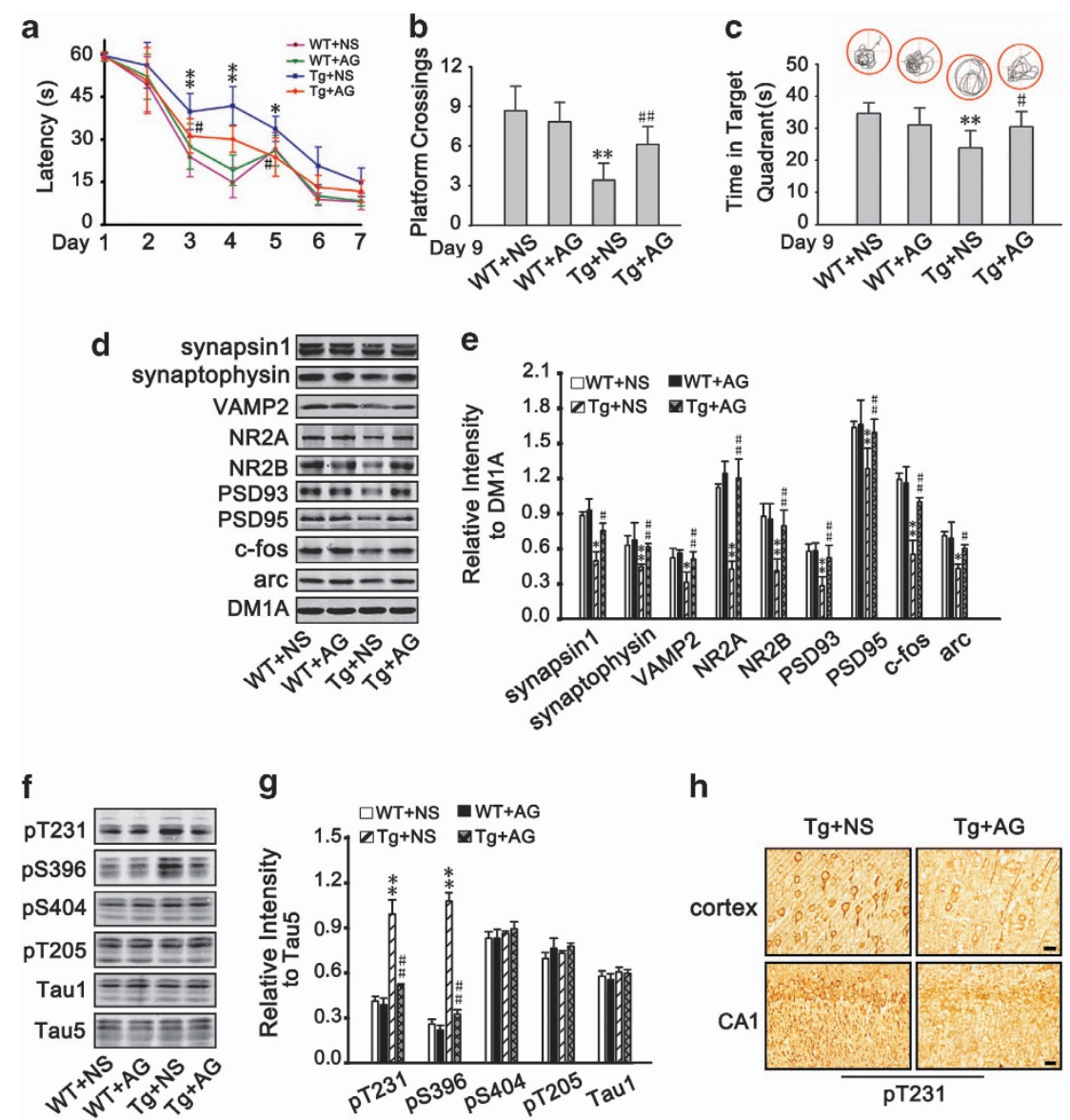

Figure 6 Subcutaneous injection of AG improves spatial memory and neuropathology in Tg2576 mice. (a and b) Tg2576 (Tg) mice and the wild-type (WT) littermates at 6-month old were subcutaneously injected with AG or NS for 3 months, then the spatial learning and memory were measured by Morris water maze. The mice were trained to remember the hidden platform in the maze for 6 days (learning process) and the latency (time to find platform) was recorded (a). The platform was removed at ninth day and the spatial memory was tested by measuring the time of platform quadrant crossing, the time stayed in the target quadrant and swimming paths (b and $\mathbf{c})$. (d and $\mathbf{e})$ The levels of presynaptic proteins (synapsin1, synaptophysin, and VAMP-2), postsynaptic proteins (NR2A, NR2B, PSD93, and PSD95) and the memory-related molecules (c-fos and arc) in hippocampus were measured by western blot and normalized against DM1A. (e and f) The phosphorylation levels of tau at Thr231, Ser396, Ser404, Thr205, and Tau-1 (Ser198/199/202) in hippocampus were measured by using phosphorylation site-specific antibodies as indicated in the blots normalized against total tau probed by Tau-5. (g) Slices of Tg mice treated with AG or NS were immunostained with antibody against phosphorylated tau at Thr231. b, c: $n=8 ; \mathbf{d}-\mathbf{g}: n=3$. ${ }^{*} P<0.05$, ${ }^{\star *} P<0.01$ versus WT + NS group; ${ }^{\#} P<0.05,{ }^{\# \#} P<0.01$ versus $\mathrm{Tg}+$ NS group. s: second in a and $\mathbf{c}$. Scale bar in $\mathbf{h}, 50 \mu \mathrm{m}$ a

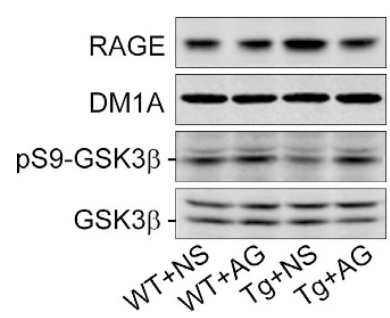

Figure 7 Inhibition of A $\beta$-AGE formation suppresses RAGE upregulation and GSK$3 \beta$ activation in Tg2576 mice. Tg2576 (Tg) or wild-type (WT) mice at 6-month old were injected subcutaneously with AG or NS for 3 months. At 9 month old, the mice were killed and levels of RAGE and the phosphorylated GSK-3 $\beta$ at Ser 9 were estimated by westem blot. RAGE and pS9-GSK-3 $\beta$ were normalized, respectively, to DM1A and total GSK-3 $\beta . n=3 .{ }^{*} P<0.01$ versus WT + NS group. ${ }^{\#} P<0.01$ versus $\mathrm{Tg}+$ NS group

data imply that RAGE may have an important role in exacerbating the toxic effect of $A \beta$-AGE.

GSK-3 has been verified to participate in the pathogenesis of $\mathrm{AD} .{ }^{43,44}$ Upregulation of GSK-3 inhibits long-term potentiation and causes memory deficit. ${ }^{45}$ Based on our previous study that AGEs contribute to memory impairment through RAGE-mediated GSK-3 activation, ${ }^{21}$ we speculate that, with upregulation of RAGE, GSK-3 may be implicated in the exacerbated neural damages induced by $A \beta$-AGE. Indeed, our results showed that GSK-3 in hippocampal neurons in vitro was activated and simultaneous application of GSK-3 inhibitor attenuated the exacerbated pathological change of $A \beta-A G E$, suggesting the involvement of RAGEdependent GSK-3 activation pathway. We also observed a more significant inhibition of Akt by $\mathrm{A} \beta$-AGE than $\mathrm{A} \beta$. The activity of GSK-3 is regulated by phosphatidyl inositol 3 kinase-Akt pathway, ${ }^{22}$ and upregulation of Akt attenuates the AGE-induced dysfunction of endothelial progenitor cells, ${ }^{46}$ which supports our data.

The in vitro results have shown that $\mathrm{A} \beta$ was the suitable substrate for the glycation and glycated $A \beta$ appeared to be more neurotoxic than $A \beta$. Thus, we speculated that AGEs may be produced by glycating $\mathrm{A} \beta$ even in the early stage of Tg2576 mice, in which accumulation of $\mathrm{A} \beta$ contributes to the 
pathology. To test this, we measured the levels of AGEs and glycation of $A \beta$ in hippocampus of Tg2576 mice. We found that the level of AGEs increased age dependently started from 9-month-old onward of the mice, and $\mathrm{A} \beta$ was co-immunoprecipitated with AGEs, suggesting $A \beta$ is glycated to form $A \beta$ $A G E$. To verify the toxic role of $A G E s$, we used $A G$, an inhibitor of AGEs that can block glycation of proteins or peptides by glucose or its derivants, to suppress formation of AGEs. The AG was administrated subcutaneously for 3 months, started at 6 months old when the AGEs level was normal. We observed that infusion of AG decreased levels of AGEs and $\mathrm{A} \beta$-AGE in hippocampus with significant improvement of spatial learning and memory of the mice. Simultaneously, levels of the hyperphosphorylated tau, synaptic, and memoryrelated proteins were remarkably restored in the hippocampus of mice. We also carried out the above experiments in the cortex of mice, the result of which was consistent with that in hippocampus. These data suggest that formation of $A \beta$-AGE may exaggerate $A D$ pathologies.

In view of observation of amplified RAGE-mediated GSK-3 activation induced by $A \beta$-AGE in hippocampal neurons, we also examined the expression of RAGE and GSK-3 in AGtreated Tg2576 mice. We found that inhibition of $A \beta$-AGE formation could attenuate upregulation of RAGE and activation of GSK-3, which provides the in vivo data supporting the participation of RAGE/GSK-3 pathway in the exacerbated neural dysfunctions induced by $A \beta$-AGE. We also found that the levels of $A \beta 1-40$ and $A \beta 1-42$ decreased with inhibition of AGEs. A recent study show that inhibition of RAGE with RAGE antibody or RAGE knockout could downregulate $\beta$-site APP cleaving enzyme 1 (BACE1), ${ }^{47}$ whereas activation of RAGE upregulate BACE $1,{ }^{48}$ which may partially explain the decreased $A \beta$ after $A G$ treatment observed in the current study.

$\mathrm{A} \beta$ is found in extracellular SP cores and is associated with neurodegeneration in later stages of $A D$. In contrast, recent studies suggest that accumulation of intraneuronal $A \beta$ may be an early event in the pathogenesis of $A D .{ }^{49,50}$ RAGE mediates intraneuronal transport of $A \beta$ and neuronal dysfunction. ${ }^{12}$ The above studies demonstrate that $\mathrm{A} \beta$ also exits inside the neurons, especially in the early stage of AD. Oxidative stress and glucose metabolism disorder in $A D$ lead to intracellular production of carbonyl compounds, which could modify intracellular $\mathrm{A} \beta$ to form $\mathrm{A} \beta$-AGE. This may explain why we observed numerous AGEs inside the neurons.

In summary, we have found for the first time that the formation of $A \beta$-AGE exacerbates the toxicity of $A \beta$ with the mechanisms involving activation of RAGE/GSK-3 pathway, and inhibition of $A G E s$ including $A \beta$-AGE can restore the cognitive deficit in $A D$-like model mice, which reveal that the underlying mechanism of $T 2 D$ to be related to $A D$ may be through increasing formation of $\mathrm{A} \beta$-AGE.

\section{Materials and methods}

Antibodies and chemicals. Mouse monoclonal antibody (mAb) AGE was from Tans Genic.Inc (Kumamoto, Japan). Rabbit polyclonal antibody (pAb) against tau phosphorylated at Ser396, Ser404, Thr231, and Thr205 were from Biosource (Camarillo, CA, USA). mAb Tau1 against tau unphosphorylated at Ser198/199/ 202, RAGE, and synapsin I were from Millipore (Billerica, MA, USA). mAb Tau5 against total tau was from Lab Vision Corp (Fremont, CA, USA). pAb GSK-3,
pS9-GSK-3 $\beta$, pS473-Akt, total Akt, and c-fos were from Cell Signaling Technology (Beverly, MA, USA); pAb A $\beta$, pT308-Akt, NR2A, NR2B, PSD93, PSD95, VAMP2, and Arc were from Abcam (Cambridge, UK). mAb DM1A against $\alpha$-tubulin and mAb synaptophysin were from Sigma (St Louis, MO, USA). Peptide A $\beta 1-42$ was from ChinaPeptides Co., Ltd (Shanghai, China). Anti-rabbit IRDye and anti-mouse IRDye were from Li-Cor Biosciences (Lincoln, NE, USA). BCA kit was from Pierce (Rockford, IL, USA). Peroxidase-conjugated goat anti-rabbit and goat anti-mouse secondary antibodies were from Pierce (Rockford, IL, USA). Neurobasal and B27 were from Gibco (Grand Island, NY, USA).

Animals and treatment. APP transgenic mice (Tg2576 Mice) were obtained from the Jackson Laboratory (Bar Harbor, ME, USA). These mice overexpress human APP695 with a double mutation KM670/671NL. All mice were produced by the Experimental Animal Center of Tongji Medical College. The genotype was confirmed by PCR analysis of tail biopsies. All mice were kept under standard laboratory conditions: $12 \mathrm{~h}$ light and $12 \mathrm{~h}$ dark; lights on at 0600 hours; temperature: $22 \pm 2{ }^{\circ} \mathrm{C}$; water and food ad libitum. All animal experiments were performed according to the 'Policies on the Use of Animals and Humans in Neuroscience Research' revised and approved by the Society for Neuroscience in 1995.

Six-month Tg2576 or control C57BL mice were subcutaneously injected with $0.1 \mu \mathrm{l} \mathrm{NS}$ or AG $(20 \mathrm{mg} / \mathrm{ml})$ at 1000 hours for 3 months. Then, mice were trained for morris water maze test.

Preparation of A $\beta$-AGE. A $\beta$-AGE was prepared by incubating $100 \mathrm{mg} / \mathrm{ml}$ of $\mathrm{A} \beta 1-42$ with or without $0.5 \mathrm{~mm} M \mathrm{MG}$ in $0.1 \mathrm{M}$ phosphate buffer, $\mathrm{pH} 7.2$, at $37^{\circ} \mathrm{C}$ for 1 month under sterile condition. After dialyzed against phosphate buffer for $48 \mathrm{~h}$ to remove $M G$, the prepared $A \beta$-AGE was sterilized by filtration and kept at $-20^{\circ} \mathrm{C}$. The production of $A \beta$-AGE was identified with western blot and fluorescence spectrophotometer measuring AGE-specific fluorescence at emission of $440 \mathrm{~nm}$ and excitation of $370 \mathrm{~nm}$ (Perkin-Elmer, Waltham, MA, USA).

CD spectroscopy. $C D$ spectra from $A \beta$ or glycated $A \beta(0.1 \mathrm{mg} / \mathrm{ml})$ in water were taken using Jasco J-810 spectrapo-larimeter (Jasco international Co. Ltd, Tokyo, Japan). The CD spectrum was recorded in the range of 190-250 nm using a $0.1 \mathrm{~cm}$ path length quartz cuvette at $25^{\circ} \mathrm{C}$ in continuous scanning mode. The acquisition parameters were $100 \mathrm{~nm} / \mathrm{min}$, with a 1.0 -s response and a $1.0 \mathrm{~nm}$ band width. The data were accumulated over 10 runs, the presented data being the average. The results were expressed in term of molecular ellipticity $[\theta]$ in unit of deg. $\mathrm{cm}^{2} / \mathrm{dmol}$.

Cell culture and treatment. Embryonic hippocampal neurons were cultured according to the procedure described previously. ${ }^{45}$ Primary hippocampal neurons at 8 DIV were treated with $\mathrm{A} \beta(100 \mathrm{~nm})$ or $\mathrm{A} \beta$-AGE $(100 \mathrm{~nm})$ for $24 \mathrm{~h}$. Then, cells were harvested for western blot and immunofluorescent staining. For investigating underlying mechanism, 8-d hippocampal neurons were pre-incubated with or without RAGE antibody $(10 \mu \mathrm{g} / \mathrm{ml})$ or $\mathrm{LiCl}(4 \mathrm{~mm})$ for $1 \mathrm{~h}$ before treatment with or without $A \beta(100 \mathrm{~nm})$ or $\mathrm{A} \beta$-AGE (100 nm) for $24 \mathrm{~h}$.

Morris water maze test. Morris water maze test was performed according to the procedure described previously. ${ }^{51}$ Briefly, the mice were trained to find a submerged platform by using a stationary array of cues outside the pool tub. The water was made opaque by using milk powder for chiaroscuro. Acquisition training consisted of a total of 28 trials, given as four spaced trials a day for 6 consecutive days. The probe tests were performed with the platform on the seventh day and by removing the platform on the ninth day. Swimming paths in probe test were monitored using an automatic tracking system. This system was used to record the swimming trace and calculate the latency to the platform and the time spent in each quadrant.

Western blot and dot blot. Hippocampus were homogenized and cells were lysed in a cooled buffer containing $10 \mathrm{~mm}$ Tris- $\mathrm{HCl}(\mathrm{pH} 7.6), 50 \mathrm{~mm} \mathrm{NaF}, 1 \mathrm{~mm}$ $\mathrm{Na}_{3} \mathrm{VO}_{4}, 1 \mathrm{~mm}$ EDTA, $1 \mathrm{~mm}$ benzamidine, and $1 \mathrm{~mm}$ phenylmethylsulfonylfluoride and protease inhibitors mixture ( $1 \mathrm{mg} / \mathrm{l}$ each of a leupeptin, protininand pepstain A). The tissue homogenates and cell lysates were added with one-third volume of sample buffer containing Tris- $\mathrm{HCl}(\mathrm{pH} 7.6) 200 \mathrm{~mm}, 8 \%$ SDS, $40 \%$ glycerol, and boiled in a water bath for $10 \mathrm{~min}$. The lysates were centrifuged at $12000 \times g$ for $15 \mathrm{~min}$ at $4{ }^{\circ} \mathrm{C}$. The protein concentration in the supernatant was measured by $\mathrm{BCA}$ kit according to manufacturer's instruction. 
For western blot, equal amounts of protein were separated by $10 \%$ SDS-PAGE $^{52}$ or tricine-SDS-PAGE (for $A \beta)^{53}$ electrophoresis, and transferred to nitrocellulose membrane. The membranes were blocked with $5 \%$ nonfat milk dissolved in TBSTween-20 (50 mm Tris-HCl, pH 7.6, $150 \mathrm{~mm} \mathrm{NaCl}, 0.2 \%$ Tween-20) for $1 \mathrm{~h}$ and probed with primary antibodies overnight at $4{ }^{\circ} \mathrm{C}$. For dot blot, ${ }^{54}$ draw grid by pencil to indicate the region to be blotted. Using narrow-mouth pipet tip, adjust proteins to the same concentration, and spot $2 \mu$ l of samples onto the nitrocellulose membrane at the center of the grid. Let the membrane dry at $37^{\circ} \mathrm{C}$.

Then the blots were incubated with anti-rabbit or anti-mouse IgG conjugated to IRDye $(800 \mathrm{CW})$ for $1 \mathrm{~h}$ at room temperature and visualized using the Odyssey Infrared Imaging System (Lincoln, NE, USA).

Co-immunoprecipitation. Cells were lysed in cooled lysis buffer $(50 \mathrm{~mm}$ Tris- $\mathrm{HCl}, \mathrm{pH} 7.4,250 \mathrm{~mm} \mathrm{NaCl}, 5 \mathrm{~mm}$ EDTA, $50 \mathrm{~mm} \mathrm{NaF}, 0.1 \mathrm{~mm} \mathrm{Na}_{3} \mathrm{VO}_{4}, 0.1 \%$ Triton $\mathrm{X}$-100) containing $1 \mathrm{~mm}$ phenylmethylsulfonylfluoride and protease inhibitors mixture for $30 \mathrm{~min}$. The cell lysates were centrifuged at $12000 \times g$ for $10 \mathrm{~min}$ at $4{ }^{\circ} \mathrm{C}$. The supernatants $(0.5 \mathrm{mg})$ were incubated with indicated antibody at $4{ }^{\circ} \mathrm{C}$ overnight with gentle rotation, then mixed $(20 \mu \mathrm{l})$ with the suspension of protein G-Sepharose beads (1:1) and incubated for $2 \mathrm{~h}$ at $4{ }^{\circ} \mathrm{C}$ with gentle rotation. The beads were collected by centrifugation and washed extensively with cell lysis buffer. The bound proteins were dissociated by boiling the beads in sample buffer and examined by dot blot.

Immunohistochemistry, immunofluorescence, and ELISA. The mice were killed by overdose of chloral hydrate and transcardially perfused with $50 \mathrm{ml} \mathrm{NS}$, and then with $100 \mathrm{ml} 4 \%$ cooled paraformaldehyde solution. The brains were post-fixed in the same fixation fluid for another $24 \mathrm{~h}$ at $4^{\circ} \mathrm{C}$. Coronal brain sections of hippocampal tissue were cut at $25 \mu \mathrm{m}$ using a vibrate microtome (VT1000S, Leica, Solms, Germany). For each primary antibody, three to five consecutive sections from each brain were used. The immunoreaction was detected using horseradish peroxidase-labeled antibodies and visualized with diaminobenzidine (Sigma) tetrachloride system. The images were observed using a microscope (Olympus BX60, Olympus, Tokyo, Japan).

For cell studies, cells were cultured on coverslips and fixed with $4 \%$ paraformaldehyde. Rhodamine red-X- or Oregon Green 488-conjugated secondary antibodies (Invitrogen, Carlsbad, CA, USA) were used for immunofluorescence. The images were visualized using a laser two-photon confocal microscope (LSM510, Zeiss, Oberkochen, Germany).

The level of $A \beta$ in cortical and hippocampal homogenates were measured by a sandwich ELISA kit using an anti-A $\beta$ N-terminal antibody and an anti-A $\beta 1-40$ or A $\beta 1-42$ C-terminal antibody, according to the manufacturer's instructions (Biosource International, Camarillo, CA, USA).

Statistical analysis. Data were analyzed by using SPSS 11.0 statistical software (SPSS, Chicago, IL, USA). Statistical significance was determined by one-way ANOVA procedure followed by Duncan's post hoc test with $95 \%$ confidence and two-tailed Student's $t$-test. All data were expressed as mean \pm S.D.

\section{Conflict of Interest}

The authors declare no conflict of interest.

Acknowledgements. This work was supported by the National Nature Scientific Fund of China (81171196), the National Key Technology Research and Development Program of the Ministry of Science and Technology of China (No 2012BAl10B03).

1. Yan SD, Chen X, Schmidt AM, Brett J, Godman G, Zou YS et al. Glycated tau protein in Alzheimer disease: a mechanism for induction of oxidant stress. Proc Natl Acad Sci USA 1994; 91: 7787-7791.

2. Chambers JK, Uchida K, Harada T, Tsuboi M, Sato M, Kubo M et al. Neurofibrillary tangles and the deposition of a Beta amyloid Peptide with a novel N-terminal epitope in the brains of wild tsushima leopard cats. PLoS One 2012; 7: e46452.

3. Glenner GG, Wong CW. Alzheimer's disease and Down's syndrome: sharing of a unique cerebrovascular amyloid fibril protein. Biochem Biophys Res Commun 1984; 122 : $1131-1135$
4. Hsiao K, Chapman P, Nilsen S, Eckman C, Harigaya Y, Younkin S et al. Correlative memory deficits, Abeta elevation, and amyloid plaques in transgenic mice. Science 1996; 274: 99-102.

5. Vitek MP, Bhattacharya K, Glendening JM, Stopa E, Vlassara H, Bucala R et al. Advanced glycation end products contribute to amyloidosis in Alzheimer disease. Proc Natl Acad Sci USA 1994; 91: 4766-4770.

6. Fawver JN, Schall HE, Petrofes Chapa RD, Zhu X, Murray IV. Amyloid-beta metabolite sensing: biochemical linking of glycation modification and misfolding. J Alzheimers Dis 2012; 30: 63-73

7. Yan SD, Yan SF, Chen X, Fu J, Chen M, Kuppusamy P et al. Non-enzymatically glycated tau in Alzheimer's disease induces neuronal oxidant stress resulting in cytokine gene expression and release of amyloid beta-peptide. Nat Med 1995; 1: 693-699.

8. Byun K, Bayarsaikhan E, Kim D, Kim CY, Mook-Jung I, Paek SH et al. Induction of neuronal death by microglial AGE-albumin: implications for Alzheimer's disease. PLoS One 2012; 7: e37917.

9. Neeper M, Schmidt AM, Brett J, Yan SD, Wang F, Pan YC et al. Cloning and expression of a cell surface receptor for advanced glycosylation end products of proteins. $\mathrm{J} \mathrm{Biol} \mathrm{Chem}$ 1992; 267: 14998-15004.

10. Shang L, Ananthakrishnan R, Li Q, Quadri N, Abdillahi M, Zhu Z et al. RAGE modulates hypoxia/reoxygenation injury in adult murine cardiomyocytes via JNK and GSK-3beta signaling pathways. PLoS One 2010; 5: e10092.

11. Yan SD, Chen X, Fu J, Chen M, Zhu H, Roher $A$ et al. RAGE and amyloid-beta peptide neurotoxicity in Alzheimer's disease. Nature 1996; 382: 685-691.

12. Takuma K, Fang F, Zhang W, Yan S, Fukuzaki E, Du H et al. RAGE-mediated signaling contributes to intraneuronal transport of amyloid-beta and neuronal dysfunction. Proc Natl Acad Sci USA 2009; 106: 20021-20026.

13. Du Yan S, Zhu H, Fu J, Yan SF, Roher A, Tourtellotte WW et al. Amyloid-beta peptidereceptor for advanced glycation endproduct interaction elicits neuronal expression of macrophage-colony stimulating factor: a proinflammatory pathway in Alzheimer disease. Proc Natl Acad Sci USA 1997; 94: 5296-5301.

14. Hadding A, Kaltschmidt B, Kaltschmidt C. Overexpression of receptor of advanced glycation end products hypersensitizes cells for amyloid beta peptide-induced cell death. Biochimica et Biophysica Acta 2004; 1691: 67-72.

15. Fang F, Lue LF, Yan S, Xu H, Luddy JS, Chen D et al. RAGE-dependent signaling in microglia contributes to neuroinflammation, Abeta accumulation, and impaired learning/ memory in a mouse model of Alzheimer's disease. Faseb J 24: 1043-1055.

16. Queisser MA, Yao D, Geisler S, Hammes HP, Lochnit G, Schleicher ED et al. Hyperglycemia impairs proteasome function by methylglyoxal. Diabetes 59: 670-678.

17. Brownlee $M$, Vlassara $H$, Kooney A, Ulrich $P$, Cerami A. Aminoguanidine prevents diabetes-induced arterial wall protein cross-linking. Science 1986; 232: 1629-1632.

18. Soulis-Liparota T, Cooper M, Papazoglou D, Clarke B, Jerums G. Retardation by aminoguanidine of development of albuminuria, mesangial expansion, and tissue fluorescence in streptozocin-induced diabetic rat. Diabetes 1991; 40: 1328-1334.

19. Rodrigues L, Biasibetti R, Swarowsky A, Leite MC, Quincozes-Santos A, Quilfeldt JA et al. Hippocampal alterations in rats submitted to streptozotocin-induced dementia model are prevented by aminoguanidine. J Alzheimers Dis 2009; 17: 193-202.

20. Webster J, Urban C, Berbaum K, Loske C, Alpar A, Gartner U et al. The carbonyl scavengers aminoguanidine and tenilsetam protect against the neurotoxic effects of methylglyoxal. Neurotox Res 2005; 7: 95-101.

21. Biosa G, Addis MF, Tanca A, Pisanu S, Roggio T, Uzzau S et al. Comparison of blood serum peptide enrichment methods by Tricine SDS-PAGE and mass spectrometry. J Proteomics 2011; 75: 93-99.

22. Baki L, Shioi J, Wen P, Shao Z, Schwarzman A, Gama-Sosa M et al. PS1 activates PI3K thus inhibiting GSK-3 activity and tau overphosphorylation: effects of FAD mutations. EMBO J 2004; 23: 2586-2596.

23. Duran-Jimenez B, Dobler D, Moffatt S, Rabbani N, Streuli CH, Thornalley PJ et al. Advanced glycation end products in extracellular matrix proteins contribute to the failure of sensory nerve regeneration in diabetes. Diabetes 2009; 58: 2893-2903.

24. Wang SH, Sun ZL, Guo YJ, Yuan Y, Li L. PPARgamma-mediated advanced glycation end products regulation of neural stem cells. Mol Cell Endocrinol 2009; 307: 176-184.

25. Ott A, Stolk RP, van Harskamp F, Pols HA, Hofman A, Breteler MM. Diabetes mellitus and the risk of dementia: the Rotterdam Study. Neurology 1999; 53: 1937-1942.

26. Takeda S, Sato N, Uchio-Yamada K, Sawada K, Kunieda T, Takeuchi D et al. Diabetes-accelerated memory dysfunction via cerebrovascular inflammation and Abeta deposition in an Alzheimer mouse model with diabetes. Proc Natl Acad Sci USA 2010; 107: 7036-7041.

27. Profenno LA, Porsteinsson AP, Faraone SV. Meta-analysis of Alzheimer's disease risk with obesity, diabetes, and related disorders. Biol Psychiatry 2010; 67: 505-512.

28. Xu WL, von Strauss E, Qiu CX, Winblad B, Fratiglioni L. Uncontrolled diabetes increases the risk of Alzheimer's disease: a population-based cohort study. Diabetologia 2009; 52: 1031-1039.

29. Han W, Li C. Linking type 2 diabetes and Alzheimer's disease. Proc Natl Acad Sci USA 2010; 107: 6557-6558.

30. Chen G, Chen KS, Knox J, Inglis J, Bernard A, Martin SJ et al. A learning deficit related to age and beta-amyloid plaques in a mouse model of Alzheimer's disease. Nature 2000; 408: 975-979. 
31. Janus C, Pearson J, McLaurin J, Mathews PM, Jiang Y, Schmidt SD et al. A beta peptide immunization reduces behavioural impairment and plaques in a model of Alzheimer's disease. Nature 2000; 408: 979-982.

32. Westerman MA, Cooper-Blacketer D, Mariash A, Kotilinek L, Kawarabayashi T, Younkin $\mathrm{LH}$ et al. The relationship between Abeta and memory in the Tg2576 mouse model of Alzheimer's disease. J Neurosci 2002; 22: 1858-1867.

33. Srikanth V, Maczurek A, Phan T, Steele M, Westcott B, Juskiw D et al. Advanced glycation endproducts and their receptor RAGE in Alzheimer's disease. Neurobiol Aging 32 763-777.

34. Loske C, Gerdemann A, Schepl W, Wycislo M, Schinzel R, Palm D et al. Transition metalmediated glycoxidation accelerates cross-linking of beta-amyloid peptide. Eur J Biochem 2000; 267: 4171-4178.

35. Kosik KS. Alzheimer's disease: a cell biological perspective. Science 1992; 256: 780-783.

36. Zhang YJ, Xu YF, Liu YH, Yin J, Li HL, Wang Q et al. Peroxynitrite induces Alzheimer-like tau modifications and accumulation in rat brain and its underlying mechanisms. Faseb $J$ 2006; 20: 1431-1442.

37. Lue LF, Walker DG, Brachova L, Beach TG, Rogers J, Schmidt AM et al. Involvement of microglial receptor for advanced glycation endproducts (RAGE) in Alzheimer's disease: identification of a cellular activation mechanism. Exp Neurol 2001; 171: 29-45

38. Miller MC, Tavares R, Johanson CE, Hovanesian V, Donahue JE, Gonzalez L et al. Hippocampal RAGE immunoreactivity in early and advanced Alzheimer's disease. Brain Res 2008; 1230: 273-280.

39. Deane R, Du Yan S, Submamaryan RK, LaRue B, Jovanovic S, Hogg E et al. RAGE mediates amyloid-beta peptide transport across the blood-brain barrier and accumulation in brain. Nat Med 2003; 9: 907-913.

40. Arancio O, Zhang HP, Chen X, Lin C, Trinchese F, Puzzo D et al. RAGE potentiates Abetainduced perturbation of neuronal function in transgenic mice. EMBO $J 2004 ; 23$ 4096-4105.

41. Origlia N, Righi M, Capsoni S, Cattaneo A, Fang F, Stern DM et al. Receptor for advanced glycation end product-dependent activation of p38 mitogen-activated protein kinase contributes to amyloid-beta-mediated cortical synaptic dysfunction. J Neurosci 2008; 28 $3521-3530$.

42. Sasaki N, Toki S, Chowei H, Saito T, Nakano N, Hayashi Y et al. Immunohistochemical distribution of the receptor for advanced glycation end products in neurons and astrocytes in Alzheimer's disease. Brain Res 2001; 888: 256-262.

43. Onishi $\mathrm{T}$, Iwashita $\mathrm{H}$, Uno $\mathrm{Y}$, Kunitomo J, Saitoh $\mathrm{M}$, Kimura $\mathrm{E}$ et al. A novel glycogen synthase kinase-3 inhibitor 2-methyl-5-(3-\{4-[(S )-methylsulfinyl]phenyl\}-1-benzofuran-5- yl)-1,3,4-oxadiazole decreases tau phosphorylation and ameliorates cognitive deficits in a transgenic model of Alzheimer's disease. J Neurochem 2011; 119: 1330-1340.

44. Pan X, Gong N, Zhao J, Yu Z, Gu F, Chen J et al. Powerful beneficial effects of benfotiamine on cognitive impairment and beta-amyloid deposition in amyloid precursor protein/presenilin-1 transgenic mice. Brain 2010; 133: 1342-1351.

45. Zhu LQ, Wang SH, Liu D, Yin YY, Tian Q, Wang XC et al. Activation of glycogen synthase kinase-3 inhibits long-term potentiation with synapse-associated impairments. J Neurosci 2007; 27: 12211-12220.

46. Liang C, Ren Y, Tan H, He Z, Jiang Q, Wu J et al. Rosiglitazone via upregulation of Akt/ eNOS pathways attenuates dysfunction of endothelial progenitor cells, induced by advanced glycation end products. Br J Pharmacol 2009; 158: 1865-1873.

47. Cho HJ, Son SM, Jin SM, Hong HS, Shin DH, Kim SJ et al. RAGE regulates BACE1 and Abeta generation via NFAT1 activation in Alzheimer's disease animal model. Faseb $J$ 2009; 23: 2639-2649.

48. Guglielmotto M, Aragno M, Tamagno E, Vercellinatto I, Visentin S, Medana C et al. AGEs/ RAGE complex upregulates BACE1 via NF-kappaB pathway activation. Neurobiol Aging 33: e113-e127.

49. Gouras GK, Tsai J, Naslund J, Vincent B, Edgar M, Checler F et al. Intraneuronal Abeta42 accumulation in human brain. Am J Pathol 2000; 156: 15-20.

50. LaFerla FM, Green KN, Oddo S. Intracellular amyloid-beta in Alzheimer's disease. Nat Rev Neurosci 2007; 8: 499-509.

51. Brandeis R, Brandys Y, Yehuda S. The use of the Morris Water Maze in the study of memory and learning. Int J Neurosci 1989; 48: 29-69.

52. Li XH, Xie JZ, Jiang X, Lv BL, Cheng XS, Du LL et al. Methylglyoxal induces tau hyperphosphorylation via promoting AGEs formation. Neuromol Med 2012; 14: 338-348.

53. Schagger $H$. Tricine-SDS-PAGE. Nat Protoc 2006; 1: 16-22.

54. Zhou XW, Li X, Bjorkdahl C, Sjogren MJ, Alafuzoff I, Soininen $\mathrm{H}$ et al. Assessments of the accumulation severities of amyloid beta-protein and hyperphosphorylated tau in the medial temporal cortex of control and Alzheimer's brains. Neurobiol Dis 2006; 22: 657-668.

(1) (3) $\Theta$ Cell Death and Disease is an open-access journal published by Nature Publishing Group. This work is licensed under a Creative Commons Attribution-NonCommercialNoDerivs 3.0 Unported License. To view a copy of this license, visit http://creativecommons.org/licenses/by-nc-nd/3.0/ 